\title{
Sugar and Bioethanol Production from Oil Palm Trunk (OPT)
}

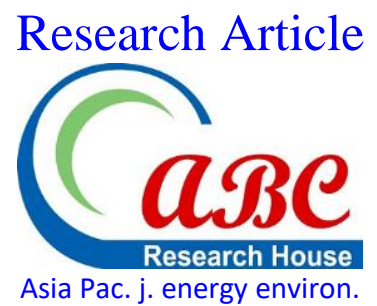

\section{Nazia Hossain ${ }^{1,2 *}$, Rafidah Jalil ${ }^{2}$}

${ }^{1}$ Department of Biotechnology-Biochemical Engineering, Faculty of Engineering, International Islamic University Malaysia (IIUM), Gombak, MALAYSIA

${ }^{2}$ Forest Research Institute Malaysia, Kepong, 52109 Selangor, MALAYSIA

*Email for Correspondence: bristy808@yahoo.com

Abstract

Various types of carbohydrate-rich plants with several methods have been experimented to produce sugar and bioethanol. Usually, sugar and bioethanol are yielded by fermentation process synthesized from cellulosic and hemi-cellulosic biomass. In this study, Oil Palm Trunk (OPT) sap was utilized to produce sugar and bioethanol using Saccharomyces cerevisiae (Yeast) as fermentation agent as well as Alanine amino acid (C3H7NO2) and Epsom salt (MgSO4) as nutritional supplements in anaerobic condition with 96 hours duration. The first objective of this study was to produce sugar and bioethanol from three different parts of OPT sap such as upper, middle and bottom part and identify the most-efficient part to optimize. Another objective was to demonstrate the effect of nutrients on fermentation process to determine highest yield. After experimenting fermentation process of $50 \mathrm{ml}$ concentrated OPT sap with $30 \mathrm{ml}$ warmed distilled water for 96 hours, obtained result indicated that upper part of OPT yielded the highest ethanol amount $58.34 \%(\mathrm{w} / \mathrm{w})$ and sugar $21.14 \%(\mathrm{w} / \mathrm{w})$ with nutrients.

Key words

Bioethanol; Sugar; Oil Palm Trunk; Fermentation; Hydrolysis

\section{INTRODUCTION}

Recently energy is known as the catalyst for development worldwide and bio-energy became very popular as we can produce it. The consumption of energy per capita is often being used as measurement of the economic development in a certain country nowadays (Pandey, Larroche, Ricke, Dussap, \& Gnansounou, 2011). Bioethanol $\left(\mathrm{C}_{2} \mathrm{H}_{5} \mathrm{OH}\right)$ is one form of renewable bioenergy, biodegradable clear-colorless liquid, eco-friendly and fast growing potential fuel to power automotive engine as well as petrol substitute for road transport vehicles. (Cheng, Hani, \& Ismail, 2007).

Oil Palm (Elaeis guineensis) is widely planted in tropical countries such as Malaysia and Indnesia for cooking oil purpose, food related industries, various detergent and cosmetics, biofuels, bioplastic materials production. Usually, oil palm plant starts giving fruits from 2.5 years after plantation and after 20-25 years fruit production gets very little. Therefore, old palm needs to be deforested, a new batch of palm plantation are afforested. To enhance oil production in Malaysian Oil Palm industries, about 120,000 ha of oil palm was estimated to be replanted annually from 2006 to 2010 in Malaysia. During replantion time, old palms are cut down, most of them are discarded or burnt at the plantation site what causes intense pollution to the environment. Therefore, effective and efficient ways to utilize this huge batch of palm plant is targeted to produce biofuel and production of bioethanol is one of those biofuels for sustainable palm oil industry (Yamada, Tanaka, Sulaiman, \& Hashim, 2010).

Fermentation is a very natural metabolic process where an organism converts complex carbohydrate into simple sugar and sugar into an alcohol or an acid. In this study, two reactions are basic ingredients in converting cellulosic OPT sap into bioethanol by enzymatic hydrolysis and fermentation process. Usually enzymatic hydrolysis is a catalytic decomposition of chemical compound by reaction with water. Hydrolysis converts complex polysaccharides (sugar) into simple sugar as middle metabolic reaction here (Borglum, 2010). It is a series biocatalyzed reaction aided by yeast because yeast contains enzyme invertase which acts as catalyst and helps to 
convert the sucrose sugars into glucose and fructose. Later on, glucose converts into ethanol and carbon dioxide in the anaerobic environment. The series bio-catalytic reaction is written as follow:

$$
\mathrm{C}_{6} \mathrm{H}_{12} \mathrm{O}_{6} \text { (glucose) } \stackrel{\text { ana erobic condition }}{\longrightarrow} 2 \mathrm{C}_{2} \mathrm{H}_{5} \mathrm{OH} \text { (ethanol) }+2 \mathrm{CO}_{2} \text { (carbon dioxide) }
$$

Various species of Saccharomyces have been used for fermentation process as they are very effective for converting complex sugar to ethanol and among them Saccharomyces cerevisiae is experimented as the most efficient (Cheng, Hani, \& Ismail, 2007). Besides, nutritional supplements Alanine amino acid $\left(\mathrm{C}_{3} \mathrm{H}_{7} \mathrm{NO}_{2}\right)$ and Epsom salt $\left(\mathrm{MgSO}_{4}\right)$ were being used in this experiment to trigger yeast reaction for higher production of sugar and bioethanol.

\section{Materials AND Methods}

\section{Sample Preparation}

A fresh Oil Palm Trunk aged around 22 years old was timbered out and logged at FRIM saw mill, Kepong, Selangor, Malaysia. The whole trunk was cut into 3 pieces - Top, Middle and Bottom Part. These 3 different sized logs were handled separately in with similar processing. Each part was chopped into small sizes by Mubarak chopper and those pieces were placed into the squeezer machine to squeeze. Squeezer had two exit pathways - one path exited out the wood sap, other one exited wood residue. The used sample of this study was starchy wood sap. A germ-free sieve was used to collect the sap in a pot from squeezer; sieve separates small woody particles from raw wood juice. The pure juice was brought to Bioenergy Laboratory, $3000 \mathrm{ml}$ of it was placed in a beaker, was hit on a hot plate at temperature $100^{\circ} \mathrm{C}$ with $3-4$ hours stirring to kill microbes and concentrate the wood juice. Then it was left to cool down, collected in an airtight jar and preserved into the freezer for further usage.

\section{Analysis}

$50 \mathrm{ml}$ concentrated OPT sap was taken for each sample and poured into the conical flask. $1 \mathrm{~g}$ of Saccharomyces cerevisiae (Yeast) was measured and $30 \mathrm{ml}$ distilled water was warmed up. Yeast and warmed distilled water was added to the flask with sample and shaken it a bit. The flask was air-tightly closed with cotton and covered it with aluminium foil to prepare anaerobic condition. Orbital shaker was set up at agitation rate $160 \mathrm{rpm}$, temperature $37^{\circ} \mathrm{C}$ for 96 hours (4 days) and set up to make 'BEEP' sound for every 24 hours (1 day) to check the sample and put the flask into the shaker. The 'AC' button was switched on, 'PLAY' button was pressed to shake the mixture well. After 24 hours, when the shaker gave 'BEEP' sound, shaker was opened; flask was taken out and measured the sugar \& ethanol percentage by cleaned Pocket Refractometer PAL-1 (sugar) \& PAL-34S (ethanol). Put the flasks in orbital shaker \& press 'PLAY' again for another 24 hours. This whole procedure was being conducted for four days continuously and the record was jot down. For the sample with nutrients, $1 \mathrm{~g}$ of Alanine amino acid $\left(\mathrm{C}_{3} \mathrm{H}_{7} \mathrm{NO}_{2}\right)$ and $1 \mathrm{~g}$ of Epsom salt $\left(\mathrm{MgSO}_{4}\right)$ was added with sample of $1 \mathrm{~g}$ Saccharomyces cerevisiae (Yeast), 30ml warmed distilled water and $50 \mathrm{ml}$ concentrated OPT sap mixture and other procedures were being conducted in similar way like sample without nutrients.

\section{Result AND Discussion}

This experiment yielded higher glucose and ethanol content based on the increase of fermentation period what shows that the starchy part of OPT sap hydrolyzed into simple sugars, the carbon source of sugar was indeed the nutrient for yeast fermentation process. In anaerobic fermentation, a huge amount of substrate carbon was broken down and converted into ethanol.

Table-1: Percentage of Sugar \& Ethanol Content without nutrients

\begin{tabular}{|l|l|l|l|l|l|}
\hline OPT parts & $\begin{array}{l}\text { Percentage } \\
(\%)\end{array}$ & $\begin{array}{l}24 \text { hours } \\
\left(1^{\text {st }} \text { Day }\right)\end{array}$ & $\begin{array}{l}48 \text { hours } \\
\left(2^{\text {nd }} \text { Day }\right)\end{array}$ & $\begin{array}{l}72 \text { hours } \\
\left(3^{\text {rd }} \text { Day }\right)\end{array}$ & $\begin{array}{l}96 \text { hours } \\
\left(4^{\text {th }} \text { Day }\right)\end{array}$ \\
\hline Upper & Ethanol & 38.5 & 38.0 & 39.0 & 41.0 \\
\hline Middle & Sugar & 14.7 & 14.9 & 14.9 & 15.2 \\
\hline & Ethanol & 28.5 & 29.0 & 29.5 & 30.5 \\
\hline Bottom & Eugar & 11.8 & 11.9 & 11.9 & 12.2 \\
\hline & Sugar & 12.4 & 12.5 & 12.7 & 12.7 \\
\hline
\end{tabular}

Based on Table-1, in all parts of OPT sap, ethanol productivity was more than $30 \%(\mathrm{w} / \mathrm{w})$, sugar productivity was up to $15.2 \%(\mathrm{w} / \mathrm{w})$. Table-1 also showed that Upper part of OPT contained highest ethanol $41 \%(\mathrm{w} / \mathrm{w})$ and glucose $15.2 \%(\mathrm{w} / \mathrm{w})$ at 96 hours of fermentation period. It proved that Upper OPT is more efficient for both sugar and 
ethanol production than other parts of OPT here, $96 \mathrm{hr}\left(4^{\text {th }}\right.$ Day) is the optimized condition for hydrolysis as well as fermentation process of this experiment.

In the second batch of fermentation, nutritional supplements Alanine amino acid $\left(\mathrm{C}_{3} \mathrm{H}_{7} \mathrm{NO}_{2}\right)$ and Epsom salt $\left(\mathrm{MgSO}_{4}\right)$ were added and by the experimental result, it was proved that yeast got extra nutrition and catalyst of yeast signaled higher production rate for both ethanol and sugar content.

Table-2: Percentage of Sugar \& Ethanol Content with nutrients

\begin{tabular}{|l|l|l|l|l|l|}
\hline $\begin{array}{l}\text { OPT } \\
\text { parts }\end{array}$ & $\begin{array}{l}\text { Percentage } \\
(\%)\end{array}$ & $\begin{array}{l}24 \text { hours } \\
\left(1^{\text {st }} \text { Day }\right)\end{array}$ & $\begin{array}{l}48 \text { hours } \\
\left(2^{\text {nd }} \text { Day }\right)\end{array}$ & $\begin{array}{l}72 \text { hours } \\
\left(3^{\text {rd }} \text { Day }\right)\end{array}$ & $\begin{array}{l}96 \text { hours } \\
\left(4^{\text {th }} \text { Day }\right)\end{array}$ \\
\hline Upper & Ethanol & 51.0 & 58.34 & 53.0 & 49.34 \\
\hline & Sugar & 20.34 & 20.6 & 21.2 & 21.14 \\
\hline Middle & Ethanol & 42.67 & 44.84 & 45.84 & 45.17 \\
\hline & Sugar & 16.24 & 16.77 & 16.87 & 16.97 \\
\hline Bottom & Ethanol & 45.34 & 47.0 & 46.0 & 43.0 \\
\hline & Sugar & 16.74 & 17.34 & 17.17 & 17.4 \\
\hline
\end{tabular}

Table-2 shows that with the addition of nutrients to the sample, enzymatic hydrolysis and fermentation process triggered to action from 24 hours. Again, here Upper OPT contained the highest sugar and ethanol rate what proved Upper OPT is efficient for production optimization for both cases. Besides, Table-2 has demonstrated that ethanol production peaked at 48 hours ( $2^{\text {nd }}$ Day) and sugar production was peaked at 96 ours ( $4^{\text {th }}$ Day). To describe this phenomenon, it is stated that after the certain period of fermentation time, with the slowing down of nutrients supply, yeast activity started to fall.

With nutrients, the sample sugar and ethanol content is higher than without nutrients, this change happened in all parts of OPT. As nutrients were mixed with the sample, yeasts became more active and digested more sugar and produced more ethanol as nutrients are the food of yeast. Since Upper OPT showed the highest productivity in both batches of fermentation, here ethanol and sugar content comparison is visualized in below figure.

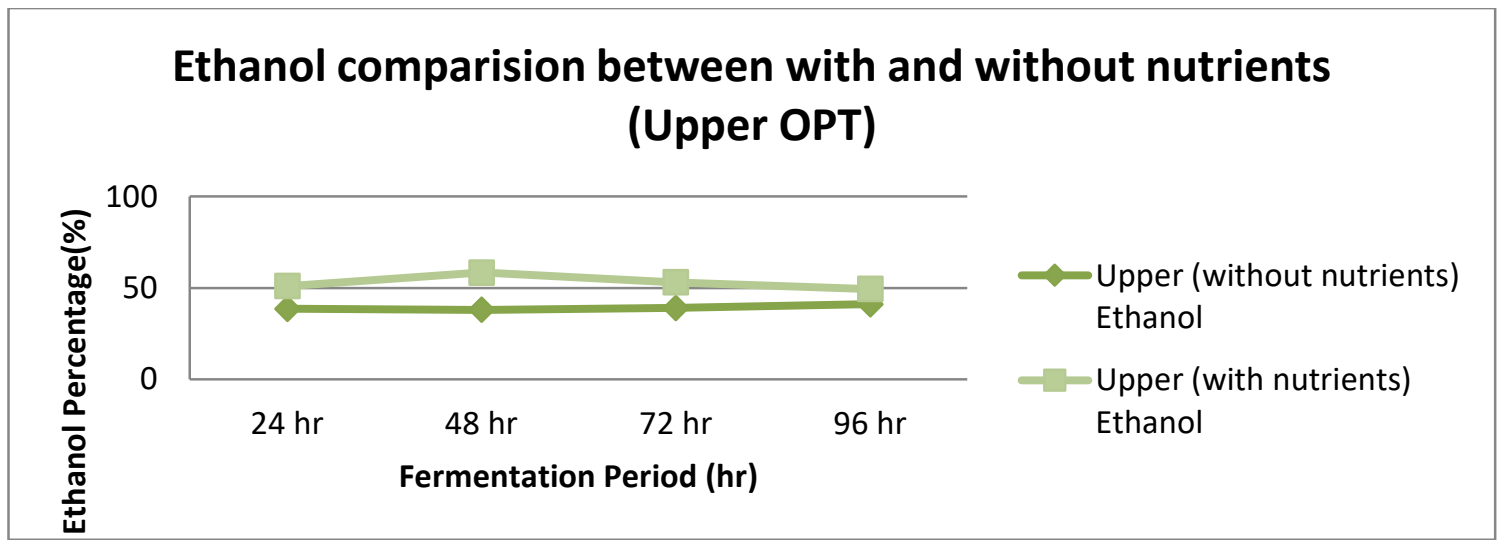

Figure-1: Ethanol comparison between with \& without nutrients (Upper)

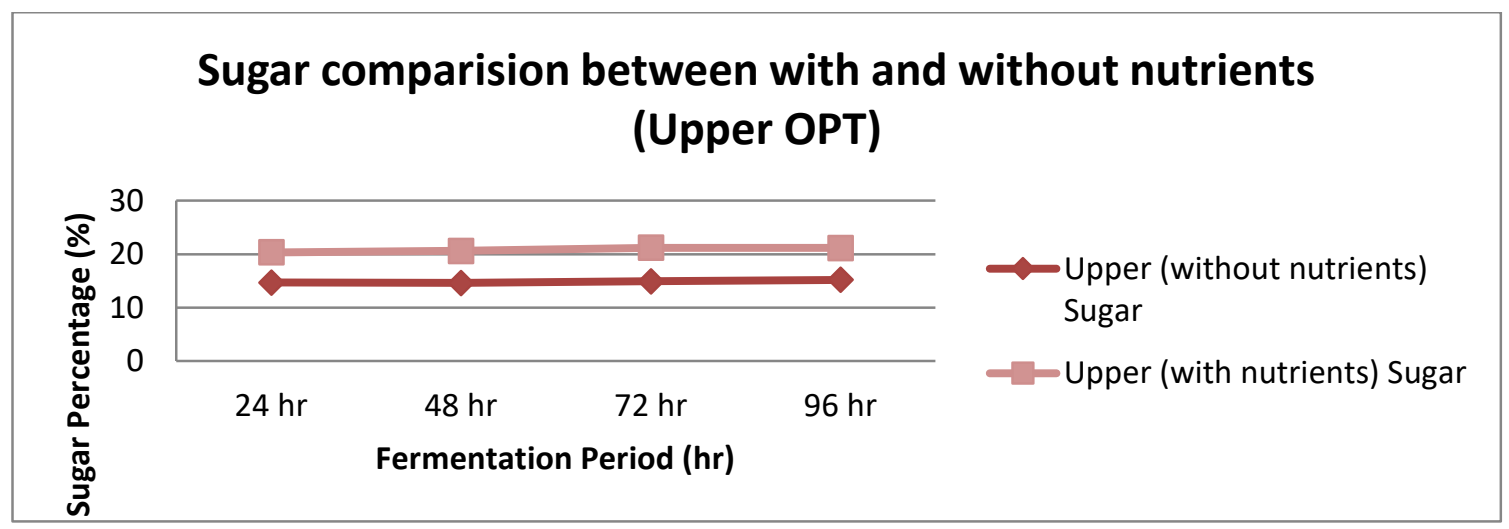

Figure-2: Sugar comparison between with \& without nutrients (Upper) 


\section{CONCLUSION}

A significant amount of sugar and bioethanol successfully produced from series bio-catalytic reactions via enzymatic hydrolysis and fermentation process. Enzymatic hydrolysis and fermentation were done with Saccharomyces cerevisiae (Yeast) as fermentation agent with the presence of warmed distilled water and additional nutritional supplements Alanine amino acid $\left(\mathrm{C}_{3} \mathrm{H}_{7} \mathrm{NO}_{2}\right)$ and Epsom salt $\left(\mathrm{MgSO}_{4}\right)$. Nutrients activated the fermentation process very highly and efficiently. The whole experiment also proved that Upper OPT provided the highest ethanol content $58.43 \%$ $(\mathrm{w} / \mathrm{w})$ and sugar content $21.14 \%(\mathrm{w} / \mathrm{w})$. As the amount of sugar and bioethanol produced from Upper OPT is quite high as well as it is an interesting traditional process converting wastage biomass to efficient bio-fuel, further work will be recommended to evaluate the economic potential of this process. Optimization of fermentation process with different parameter conditions such as $\mathrm{pH}$, temperature, reaction time, agitation speed, catalyst etc. will recommended as well what may help to deduct the cost and find the optimum condition for the glucose utilization for the ethanol \& sugar satisfactory yields \& productivity.

\section{ACKNOWLEDGEMENTS}

This work supported by the Bio-energy Laboratory of Production Department of Forest Research Institute Malaysia (FRIM).

\section{REFERENCES}

Borglum GB (2010). Starch Hydrolysis for Ethanol Production.

Cheng C, Hani HH, \& Ismail SK (2007). Production of Bioethanol from Oil Palm Empty Fruit Bunch.

Pandey A, Larroche C, Ricke SC, Dussap CG, Gnansounou Ed (201). Biofuels: Alternative Feedstocks and Conversion Processes.

Yamada H, Tanaka R, Sulaiman O, \& Hashim R (2010). Old Oil Palm Trunk: A Promising Source of Sugars for Bioethanol Production. Biomass and Bioenergy. 